\title{
Adenovirus infection of the large bowel in HIV positive patients
}

\author{
A Maddox, N Francis, J Moss, C Blanshard, B Gazzard
}

\begin{abstract}
Aims: To describe the microscopic appearance of adenovirus infection in the large bowel of human immunodeficiency virus (HIV) positive patients with diarrhoea.

Methods: Large bowel biopsy specimens from $10 \mathrm{HIV}$ positive patients, eight of whom were also infected with other gastrointestinal pathogens, with diarrhoea were examined, together with six small bowel biopsy specimens from the same group of patients. Eight of the patients had AIDS. The biopsy specimens were examined by light microscopy performed on haematoxylin and eosin stained and immunoperoxidase preparations, the latter using a commercially available antibody (Serotec MCA 489). Confirmation was obtained with electron microscopy.

Results: The morphological appearance of cells infected with adenovirus showed characteristic nuclear and cellular changes, although the inflammatory reaction was non-specific. Immunoperoxidase staining for adenovirus was sensitive and specific, and the presence of viral inclusions consistent with adenovirus was confirmed by electron microscopy.

Conclusions: The light microscopic features of adenovirus infection are distinctive and immunocytochemistry with a commercially available antibody is a sensitive and specific means of confirming the diagnosis. Further studies of the role of adenovirus in causing diarrhoea in these patients are indicated.
\end{abstract}

Diarrhoea and gastrointestinal symptoms are common in HIV positive patients. Almost all patients with AIDS report diarrhoea at some time during the course of their disease. Potentially causative infectious agents are recovered from $49 \%^{1}$ to $85 \%^{2}$ of these patients. There is a higher rate of detection in patients with AIDS. The association between symptoms and some of the organisms is unclear.

Adenovirus infection is a known cause of diarrhoea in children. It has also been isolated from HIV positive patients. The first suggestion of an association between adenovirus and diarrhoea or colitis in AIDS was reported in two patients in whom adenovirus was isolated from a culture of biopsy tissue. ${ }^{3}$ However, both had histological evidence of cytomegalovirus (CMV) infection, confirmed by electron microscopy and immunocytochemistry. ${ }^{4}$
Recently Janoff et al showed the presence of adenovirus infection of colonic epithelial cells in five HIV positive patients with diarrhoea, two cases of which were confirmed by electron microscopy and two by immunofluorescence of cultured colonic epithelial cells. ${ }^{5}$ We now report the histopathological, immunocytochemical, and electron microscopic findings in 10 patients with colonic epithelial adenovirus infection.

\section{Methods}

Details of patients and their clinical histories are shown in the table. All were homosexual men and all had mild to moderate proctitis on sigmoidoscopy. Two (cases 3 and 8 ) had contact bleeding. Nine of 10 had a noticeable reduction in CD4+ cells to less than $55 \mathrm{~mm}^{3}$ and eight had other gastrointestinal infections which might cause diarrhoea.

Tissue sections were prepared after standard fixation in neutral buffered formalin and processing to paraffin wax. Sections $4 \mu \mathrm{m}$ thick were stained with haematoxylin and eosin, periodic acid-Schiff and alcian blue, and examined by light microscopy. Control cases were taken from three HIV positive patients in whom no infection was found, one patient with CMV colitis, four patients with cryptosporidiosis and one patient with graft versus hostlike changes in their colorectal biopsy specimens.

Immunocytochemical studies were performed with adenovirus primary antibody (Serotec No MCA 489) at a dilution of 1 in 1000 on all test and control cases. Sections were mounted on poly-l-lysine coated slides, subjected to 15 minutes protease digestion and incubated with primary antibody for one hour. Secondary antibody and avidin-biotin complex were incubated for one hour each and after washing developed with diaminobenzidine for five minutes.

Two other control antibodies were applied to selected test and control sections: primary anti-CMV antibody (Dakopatts) using a previously described method ${ }^{4}$; and primary antiherpes simplex type 1 antibody (Dakopatts B1 14 polyclonal) at a dilution of 1 in 100 with incubation and development times as above

Staining procedures were run with known CMV and herpes simplex positive controls and negative controls of test cases without primary antibody.

Paraffin wax sections were dewaxed, rehydrated to water, postfixed in $2 \%$ aqueous osmium tetroxide and then dehydrated in 


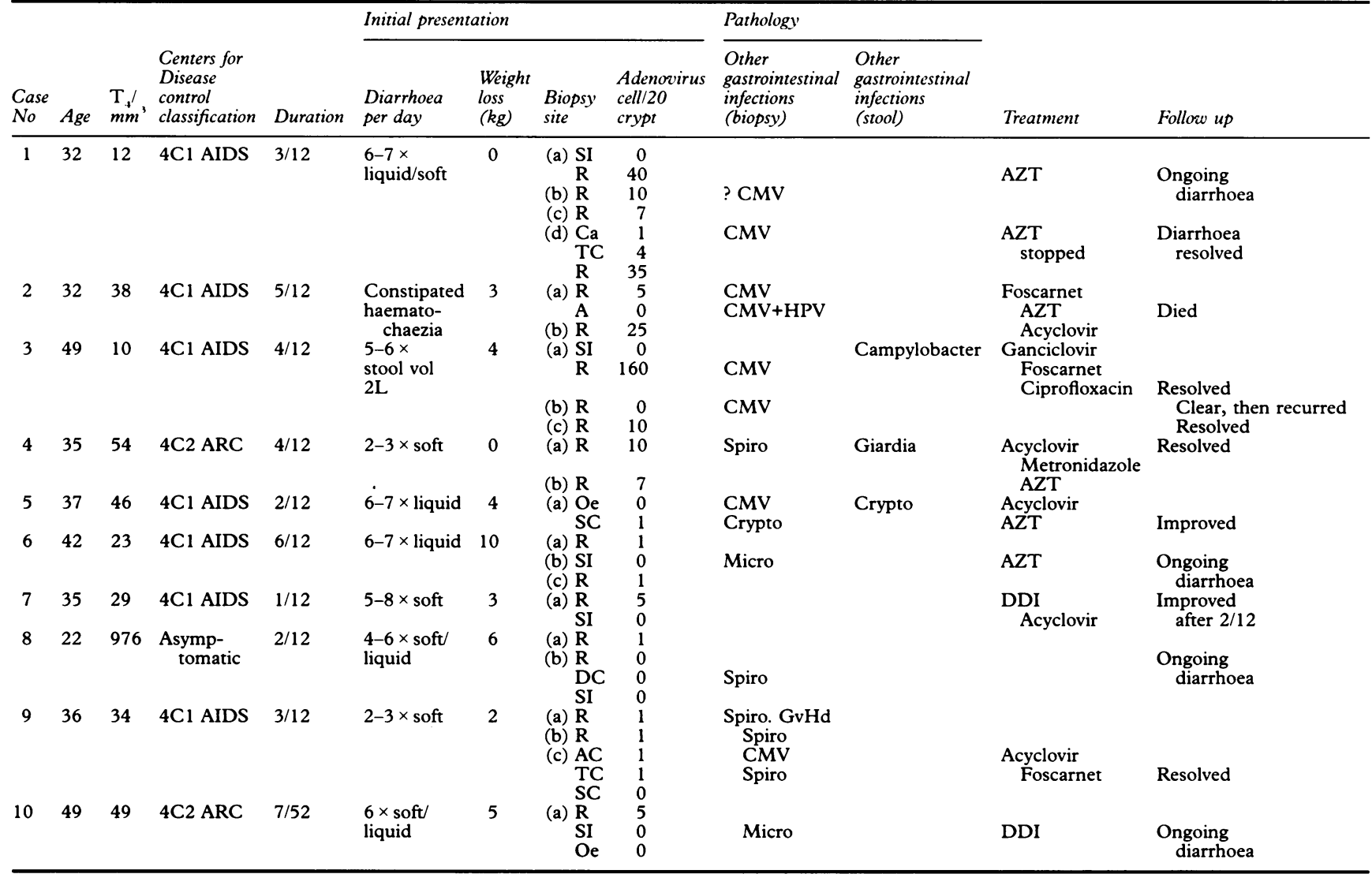

Key

Oe: Oesophagus, SI: Small intestine, Ca: Caecum, AC: Ascending colon, TC: Transverse colon, DC: Descending colon, SC: Sigmoid colon, R: Rectum, A: Anus, HPV: Human papillomavirus, GvHd: Graft versus host disease, AZT: Azidothymidine (Zidovudine), DDI: Dideoxyinosine, Spiro: Spirochaetosis, Crypto: Cryptosporidiosis, Micro: Microsporidiosis.

ascending grades of ethanol. The tissue was embedded by inverting a capsule of Spurr's resin over the selected area of the section (chosen by light microscopy), and polymerised overnight at $60^{\circ} \mathrm{C}$. The embedded material was removed from the glass slide by repeated application of steam and a rod cooled in liquid nitrogen to the underside of the slide. Ultrathin sections were stained with aqueous uranyl acetate and Reynold's lead citrate and then examined by transmission electron microscopy.

Results (table)

LIGHT MICROSCOPY

All but one of the cases were identified as

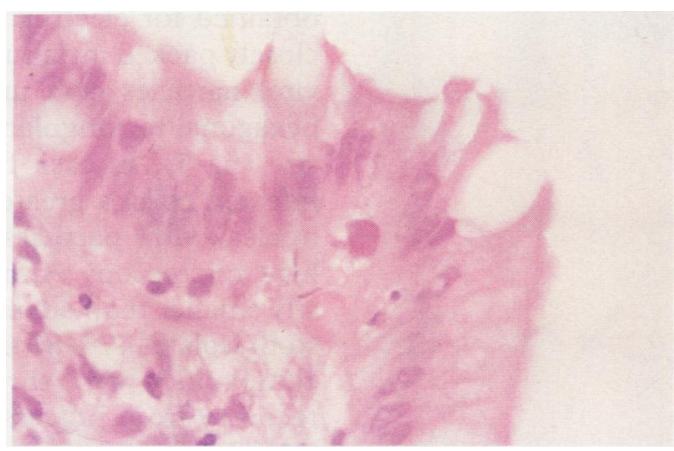

Figure 1 Cell infected with adenovirus with irregular amphophilic nucleus (note basal position) (haematoxylin and eosin). having abnormal cells in the superficial epithelial layer at the time of light microscopic examination. One case was discovered in a patient with graft-versus-host-like changes in the control group after adenovirus antibody immunocytochemical staining, but on review of the haematoxylin and eosin stained sections abnormal cells were recognisable.

The morphology of the infected cells and the associated histological changes in the large bowel mucosa are illustrated in figs 1 and 2 . The infected cells were almost always in the surface epithelium or crypt mouth and the nuclei often located immediately adjacent to the basement membrane. In one case we found an infected cell in the base of a crypt. We found no infected endothelial or stromal cells, in

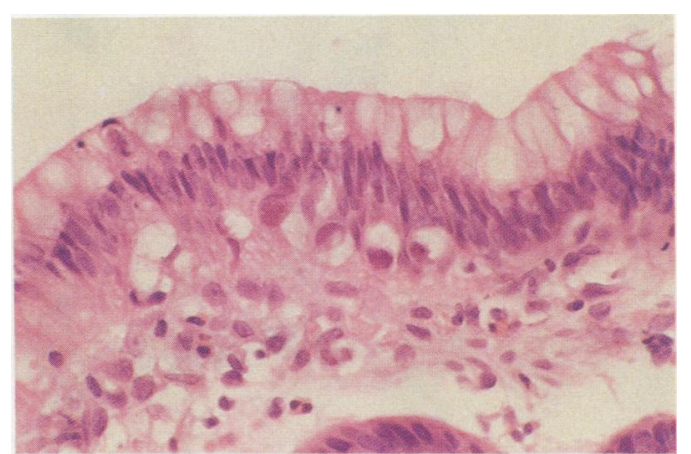

Figure 2 Six infected cells displaying crescentic nuclei in vacuolated cytoplasm (haematoxylin and eosin). 


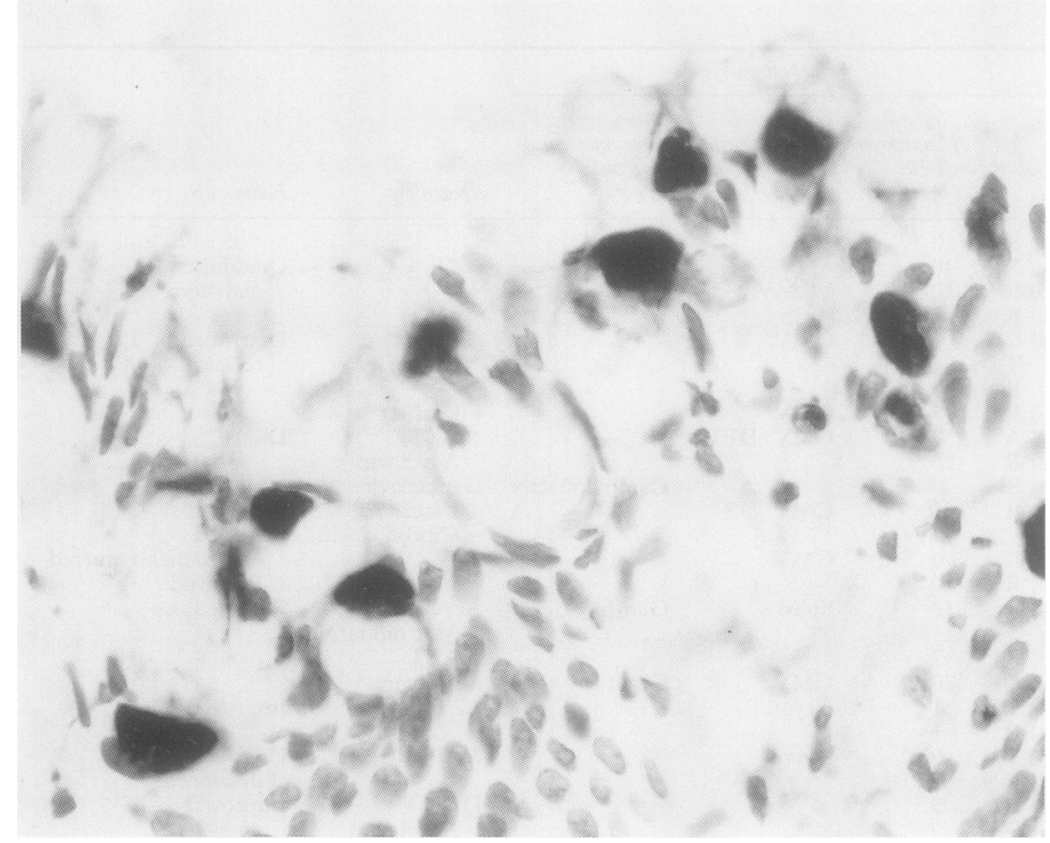

Figure 3 Multiple infected cells showing strongly positive nuclear staining with adenovirus monoclonal antibody (immunoperoxidase).

contrast to CMV. Because the cytoplasm is usually filled with mucin and vacuolated, the low power appearance is that of a goblet cell lying below the level of epithelial nuclei in that area. The nuclear changes range from that of a crescent or sickle-shaped amphophilic nucleus within a vacuolated cytoplasm to a moderately enlarged nucleus with an irregular outline which appears amphophilic at low power, but which at high power often resolves into a number of variably sized small intranuclear inclusions; these may coalesce and fill the nucleus. These two extremes of nuclear morphology probably represent the same changes seen in different planes. With mucin stains, the

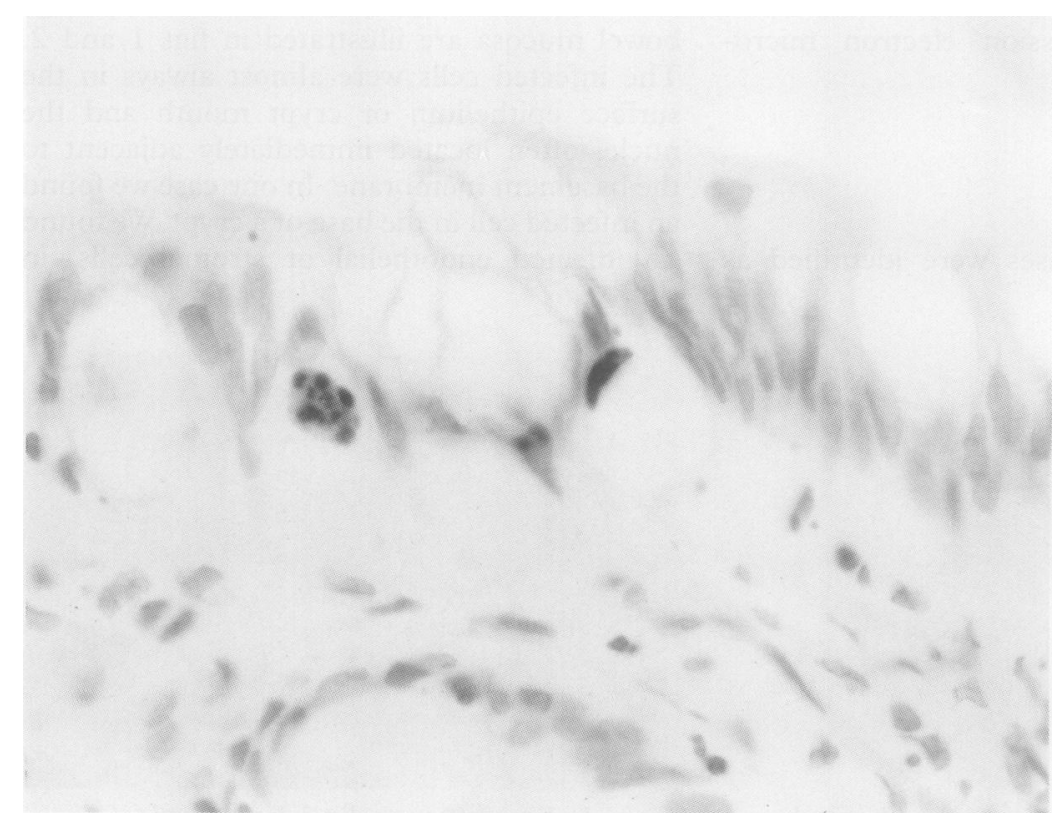

Figure 4 Three infected cells showng individual nuclear inclusions positive with adenovirus antibody (immunoperoxidase). vacuolar areas of the cytoplasm were positive for acid sialomucins (normal for the site).

The associated mucosal appearances were rather non-specific and involved a mild to moderate chronic inflammatory infiltrate. Neutrophils were only occasionally present. The epithelium showed some disarray, with an irregular, serrated epithelial surface, nuclear pseudostratification, and blurring of the boundary between epithelial cell base and lamina propria. There was a variable degree of oedema and apoptotic nuclear debris. These changes did not seem to correlate with virus load, which we estimated by counting the number of positive cells in a length of mucosa roughly equal to 20 crypt widths. In our patients this varied from 1 to 160 . Patients at either end of this scale had similar epithelial and inflammatory changes. Interestingly, and perhaps not surprisingly, the two patients with the greatest numbers of infected cells had the lowest CD4 counts. In case 1 who had colonoscopic survey with multiple biopsy specimens, the number of infected cells increased with distance from the ileo-caecal valve.

IMMUNOCYTOCHEMISTRY (table)

Optimal protease digestion, antibody dilutions, and incubation times were established using sections from case 1 in which electron microscopy had shown the presence of intranuclear viral particles of $60-80 \mathrm{~nm}$ with morphology consistent with adenovirus. The cells with cytopathic changes showed strong blackish-brown nuclear staining with the adenovirus antibody (fig 3), which often delineated individual intranuclear inclusions (fig 4) and revealed cells, particularly with a sickled nuclear morphology, that it would not be possible to ascertain were infected with adenovirus on haematoxylin and eosin staining alone. There was no positive staining in morphologically normal cells and there was no false positive staining of the CMV or herpes control cases. Furthermore, in six patients duodenal biopsy specimens, obtained at the same time as the rectal ones, were consistently negative.

ELECTRON MICROSCOPY

In three cases with relatively few infected cells the cells could not be found after lifting off parts of the paraffin wax sections. In one case (case 1) infected cells were successfully obtained for electron microscopy and showed closely packed intranuclear crystalline arrays of viral particles of a uniform morphology and hexagonal/rectangular pattern, $60-80 \mathrm{~nm}$ in size (fig 5). In case 1 , with large numbers of infected cells, a greater number showed intranuclear viral particles than were detected by light microscopy. Although the size is marginally smaller than adenovirus in culture or from stool isolates $(70-80 \mathrm{~nm})$, the size difference is compatible with shrinkage artefact due to recovery from processed and fixed tissue. The particle size is too large for polyoma $(40-50$ $\mathrm{nm}$ ) or parvovirus (30-45 nm), and too small for cytomegalovirus. 


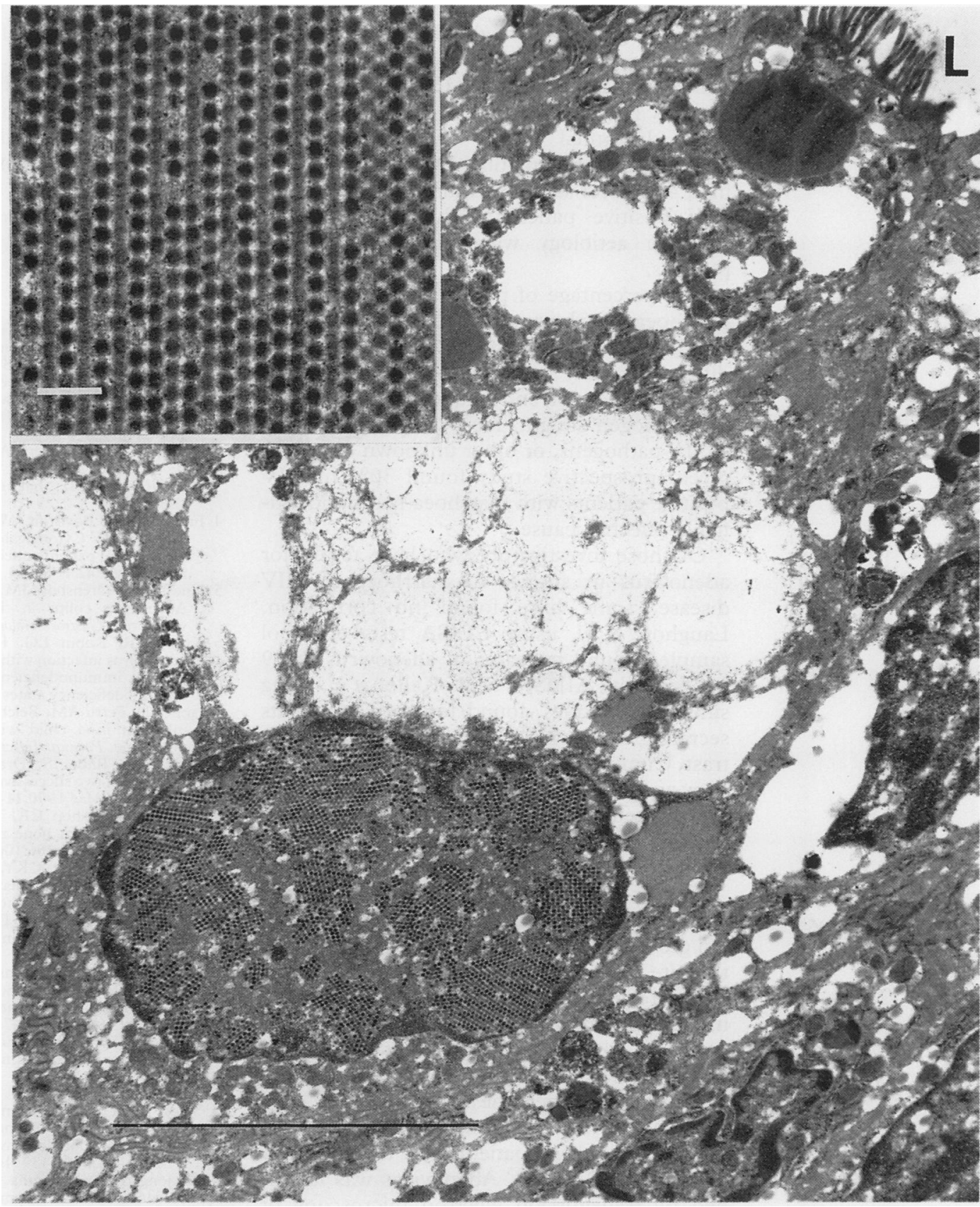

\section{Discussion}

Diarrhoea is a common and debilitating problem in patients infected with HIV, particularly those who have AIDS. The organisms commonly found include cryptosporidia, microsporidia, salmonella, Mycobacterium avium intracellulare (MAI) and cytomegalovirus (CMV). The role of adenovirus as an enteric pathogen in HIV is uncertain, although it has been implicated in fatal hepatic infection in $\mathrm{HIV}^{67}$ and in other immunodeficiency states. ${ }^{68}$ It is known to be associated with a frequently fatal gastroenteritis in bone marrow transplant recipients ${ }^{910}$ and is a common cause of respiratory tract infections and gastroenteritis in otherwise healthy children. ${ }^{112}$ In these groups with gastroenteritis adenovirus types 40 and 41 (subgenus F) are the usual isolates.

Adenovirus can be isolated from many patients with HIV disease and some of the earliest reports of AIDS mentioned this. ${ }^{13}$ Many different types are found, urine isolates often being those of subgenus $B,{ }^{15}{ }^{16}$ while stool isolates are mainly subgenus $\mathrm{D} .{ }^{16}$ Several workers have investigated the problem of diarrhoea in HIV disease to determine the proportion of patients in whom pathogens are found and to characterise these pathogens. Some have included adenovirus in their assessment. Of those that have not, Connolly et al found an infective cause in $33 \%$ of patients with AIDS related complex and $87 \%$ of patients with AIDS with non-cryptosporidial diarrhoea investigated as inpatients. ${ }^{17}$ Together with positive cryptosporidia cases reported separate$1 y,{ }^{18}$ this represents $77(72 \%)$ of a consecutive series of 107 patients with diarrhoea. Similarly, Smith et al found an infective pathogen in 17 of $20(85 \%)$ patients with AIDS with diarrhoea 
on histological and microbiological investigation.

By contrast, Rolsten et al found $38 \%$ of HIV patients had an identifiable intestinal pathogen. ${ }^{1 "}$ Intestinal biopsy specimens showed non-specific inflammation. Dryden et al examined 441 stool samples from 179 consecutive HIV positive patients with diarrhoea.' An infective aetiology was found in $49 \%$ of patients.

The percentage of patients with AIDS and diarrhoea in whom an infective cause is not found thus ranges from $15 \%$ to $51 \%$. These differences may be due to several factors, including the type and frequency of sampling, the pathogen sought, local variations in individual pathogens, or other unknown causes. A recent prospective study found $30 \%$ of HIV positive patients with diarrhoea had no identifiable infective cause. ${ }^{20}$

Of those investigators who have tested for adenovirus in studies of diarrhoea in HIV disease, some have found no correlation. Laughon et al, using ELISA tests on stool samples, found no cases of adenovirus in 49 patients with AIDS, ${ }^{21}$ while Kaljot et al, using similar techniques, found four of 77 patients secreting adenovirus in their stool. ${ }^{22}$ In contrast, Cunningham et al, using electron microscopy and culture on one or more stool samples, investigated 68 symptomatic HIV positive patients with diarrhoea and recovered adenovirus from $18 .^{23}$

The morphology of intestinal adenovirus infection is poorly described. The largest affected group are otherwise healthy children, when the site of infection is the small bowel and therefore infrequently biopsied. ${ }^{24}$ Reports of intestinal adenovirus infection in immunocompromised patients, however, point to the large bowel as the site of infection. Recently, Janoff et al have described the morphology of large bowel adenovirus infection in five of 67 homosexual HIV positive patients with diarrhoea, 51 of whom had AIDS. ${ }^{5}$ Adenovirus was identified by transmission electron microscopy or culture of the biopsy specimen with subsequent immunofluorescence. In retrospect, three of the patients at light microscopy were found to have inclusions in colonic epithelial cells which are similar to those we have described here.

The light microscopic appearances of colonic cells infected with adenovirus are distinctive and can be appreciated at low power. In particular, the basal position of the often vacuolated cells is helpful and can alert one to a more detailed examination of the nuclear morphology. Furthermore, we have shown that a commercially available monoclonal antibody will react with infected cells in formalin fixed, paraffin wax-embedded tissue and has a high degree of sensitivity and specificity.

The pathogenic role of adenovirus is still uncertain. In contrast to Janoff, $80 \%$ of our patients had another recognised enteric pathogen. All were severely immunocompromised and susceptible to a range of infections. Under these circumstances it is difficult to elicit the relative contribution, if any, of any one of a set of potential pathogens. However, the epithelial damage and disarray in areas containing cells infected with adenovirus demonstrates a cytopathic effect and therefore a possible pathogenic role on histological grounds.

We thank Pina Sannino for immunocytochemistry work, Ron Barnett for photography, and Ian Shore for electron microscopy.

1 Dryden MS, Shanson DC. The microbial causes of diarrhoea in patients infected with the human immunodeficiency virus. I Infect 1988;17:107-14.

2 Smith PD, Clifford Lane H, Gill VJ, et al. Intestinal infections in patients with the acquired immunodefiinfections in patients with the acquired immunodefi-
ciency syndrome (AIDS). Ann Intern Med ciency syndrome
1988;108:328-33.

3 Parkin J, Tyms S, Roberts A, Burnell R, Jeffries D, Pinching A. "Cytomegalovirus" colitis. Can it be caused by adenovirus? III International Conference on AIDS. 1987;1:159.

4 Francis ND, Boylston AW, Roberts AHG, Parkin JM, Pinching AJ. Cytomegalovirus infection in gastrointestinal tracts of patients infected with HIV-1 or AIDS. 7 Clin Pathol 1989;42:1055-64.

5 Janoff EN, Orenstein JM, Manischewitz JF, Smith PD. Adenovirus colitis in the acquired immunodeficiency syndrome. Gastroenterology 1991;100:976-9.

6 Krilov LR, Rubin LG, Frogel M, et al. Disseminated adenovirus infection with hepatic necrosis in patients with human immunodeficiency virus infection and other immunodeficiency states. Rev Infect Dis 1990;12:303-7.

7 Janner D, Petru AM, Belchis D, Azimi P. Fatal adenovirus infection in a child with acquired immunodeficiency syndrome. Paediatr Infect Dis F 1990;9:434-6.

8 Varki NM, Bhuta S, Drake T, Porter DD. Adenovirus hepatitis in two successive liver transplants in a child. Arch Pathol Lab Med 1990;114:106-9.

9 Yolken RH, Bishop CA, Townsend TR, et al. Infectious gastroenteritis in bone marrow transplant recipients. $N$ Engl f Med 1982;306:1009-12.

10 Landry ML, Fong CKY, Nedderman K, Solomon L, Hsiung GD. Disseminated adenovirus infection in an immunocompromised host. Am f Med 1987;83:555-9.

11 Flewett TH, Bryden AS, Davies H, Morris CA. Epidemic viral enteritis in a long-stay children's ward. Lancet 1975;i:4-5.

2 Uhnoo I, Wadell G, Svensson L, Johansson ME. Importance of enteric adenoviruses 40 and 41 in acute gastroenteritis in infants and young children. 7 Clin Microbiol 1984;20:365-72.

13 Gottlieb MS, Schroff R, Schanker HM, et al.Pneumocystis carinii pneumonia and mucosal candidiasis in previously healthy homosexual men. $N^{\prime}$ Engl $\not{f} \mathrm{Med}$ 1981;305:1425-31.

14 Siegal FP, Lopez C, Hammer GS, et al. Severe acquired immunodeficiency in male homosexuals, manifested by chronic perianal ulcerative herpes simplex lesions. $N$ Engl f Med 1981;305:1+39-44

5 de Jong PJ, Valderrama G, Spigland I, Horwitz MS. Adenovirus isolates from urine of patients with acquired immunodeficiency syndrome. Lancet 1983;i:1293-6.

16 Hierholzer JC, Wigand R, Anderson LJ, Adrian T, Gold JWM. Adenoviruses from patients with AIDS: a plethora of serotypes and a description of five new serotypes of subgenus D (types 43-47) I Infect Dis 1988;158:804-13.

17 Connolly GM, Shanson D, Hawkins DA, Harcourt Webster JN, Gazzard BG. Non-cryptosporidial diarrhoea in human immunodeficiency virus (HIV) infected patients. hut 1989;30:195-200.

18 Connolly GM, Dryden MS, Shanson DC, Gazzard BG. Cryptosporidial diarrhoea in AIDS and its treatment. Gut 1988;29:593-7.

19 Rolston KVI, Rodriquez S, Hernandez M, Bodey GP. Diarrhoea in patients infected with the human immunodeficiency virus. Am F Med 1989;86:137-8.

20 Blanshard C, Gazzard BG. An algorithm for the investigation of diarrhoea in HIV infection. Gut 1991;32:A1225.

21 Laughon BE, Druckman DA, Vernon A, et al. Prevalence of enteric pathogens in homosexual men with and without acquired immunodeficiency syndrome. Gastroenterology 1988;94:984-93.

22 Kaljot KT, Ling JP, Gold JWM, et al. Prevalence of acute enteric viral pathogens in acquired immunodeficiency syndrome patients with diarrhoea. Gastroenterology syndrome patients
1989;97:1031-42.

23 Cunningham AL, Grohmann GS, Harkness J, Law C, Marriott D, Tindall B. Gastrointestinal viral infections in Marriott D, Tindall B. Gastrointestinal viral infections in
men who were symptomatic and seropositive for human men who were symptomatic and seropositive for human
immunodeficiency virus. F Infect Dis 1988;158:386-91.

24 Philips AD. Mechanisms of mucosal injury: human studies. In: Farthing MJG, ed. Viruses and the gut. Proceedings of the Ninth International Workshop 1988. London: Smith, Kline \& French, British Society of Gastroenterology, 1988. 